\title{
Intracellular ASIC1a regulates mitochondrial permeability transition-dependent neuronal death
}

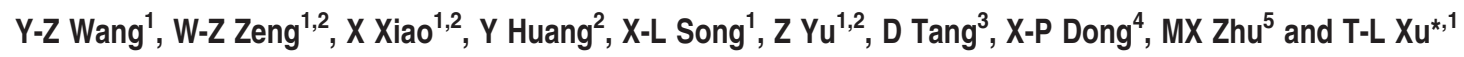

Acid-sensing ion channel 1a (ASIC1a) is the key proton receptor in nervous systems, mediating acidosis-induced neuronal injury in many neurological disorders, such as ischemic stroke. Up to now, functional ASIC1a has been found exclusively on the plasma membrane. Here, we show that ASIC1a proteins are also present in mitochondria of mouse cortical neurons where they are physically associated with adenine nucleotide translocase. Moreover, purified mitochondria from ASIC1a ${ }^{-/-}$mice exhibit significantly enhanced $\mathrm{Ca}^{2+}$ retention capacity and accelerated $\mathrm{Ca}^{2+}$ uptake rate. When challenged with hydrogen peroxide $\left(\mathrm{H}_{2} \mathrm{O}_{2}\right), A S I C 1 a^{-/-}$neurons are resistant to cytochrome $c$ release and inner mitochondrial membrane depolarization, suggesting an impairment of mitochondrial permeability transition (MPT) due to ASIC1a deletion. Consistently, $\mathrm{H}_{2} \mathrm{O}_{2}$-induced neuronal death, which is MPT dependent, is reduced in $\mathrm{ASIC1a}^{-/-}$neurons. Additionally, significant increases in mitochondrial size and oxidative stress levels are detected in $\mathrm{ASICla}^{-1-}$ mouse brain, which also displays marked changes (>2-fold) in the expression of mitochondrial proteins closely related to reactive oxygen species signal pathways, as revealed by two-dimensional difference gel electrophoresis followed by mass spectrometry analysis. Our data suggest that mitochondrial ASIC1a may serve as an important regulator of MPT pores, which contributes to oxidative neuronal cell death.

Cell Death and Differentiation (2013) 20, 1359-1369; doi:10.1038/cdd.2013.90; published online 12 July 2013

The acid-sensing ion channels (ASICs) represent a subfamily of degenerin/epithelial $\mathrm{Na}^{+}$channels that are activated by extracellular protons. ${ }^{1}$ Homomeric ASIC1a channels are expressed throughout central and peripheral nervous systems and are implicated in learning/memory, pain sensation and neuronal death. ${ }^{1-8}$ Among all these functions, mediating ischemic neuronal death was one of the most prominent pathological features of ASIC1a channels. ${ }^{5-7}$ Although it has been established that severe extracellular acidosis in ischemic brain overactivated ASIC1a and caused neuronal death, ${ }^{5,6}$ the death mechanisms remained largely unknown particularly considering that $\mathrm{ASIC} 1 \mathrm{a}$ channels completely desensitize within a few seconds during persistent acidosis. ${ }^{9}$ Thus, under such ischemic conditions, there might be other ASIC1a-associated mechanism(s) than acidosisinduced channel activation to explain the prominent effect against ischemic insult in the ASIC1a gene deletion mutant. ${ }^{5}$
Indeed, ischemic neuronal death is a consequence of numerous ionic, biochemical and cellular events. ${ }^{10,11}$ Multiple causes have been identified for neuronal demise such as excitotoxicity, acidotoxicity, oxidative stress and inflammation. ${ }^{10-12}$ The ASIC1a channels may be involved in one or more of these mechanisms.

Mitochondria are the key death executors in the cell, playing a central role in neuronal damages associated with neurological disorders such as ischemic stroke and neurodegenerative diseases. ${ }^{13}$ Mitochondrial permeability transition (MPT) is a key event that occurs in most forms of cell demise (apoptotic, necrotic, autophagic or mitotic), determining the life and death of cells. ${ }^{14-16}$ The opening of MPT pores causes an abrupt increase of inner mitochondrial membrane permeability to solutes with molecular masses of $<1500 \mathrm{Da},{ }^{14,16,17}$ leading to mitochondrial swelling, disruption of the mitochondrial outer membranes and mitochondrial dysfunction. ${ }^{14-16}$

\footnotetext{
${ }^{1}$ Departments of Anatomy and Embryology, Biochemistry and Molecular Cell Biology, Shanghai Key Laboratory for Tumor Microenvironment and Inflammation, Institute of Medical Sciences, Shanghai Jiao Tong University School of Medicine, Shanghai 200025, China; ${ }^{2}$ State Key Laboratory of Neuroscience, Institute of Neuroscience, Shanghai Institutes for Biological Sciences, Chinese Academy of Sciences, Shanghai 200031, China; ${ }^{3}$ Department of Gastroenterology, Ruijin Hospital, Shanghai Jiao Tong University School of Medicine, Shanghai 200025, China; ${ }^{4}$ Department of Physiology and Biophysics, Faculty of Medicine, Dalhousie University, 5850 College Street, Halifax B3H 4R2, Nova Scotia, Canada and ${ }^{5}$ Department of Integrative Biology and Pharmacology, The University of Texas Health Science Center at Houston, Houston, TX 77030, USA

${ }^{*}$ Corresponding author: T-L Xu, Departments of Anatomy and Embryology, Biochemistry and Molecular Cell Biology, Shanghai Key Laboratory for Tumor Microenvironment and Inflammation, Institute of Medical Sciences, Shanghai Jiao Tong University School of Medicine, 280 South Chongqing Road, Shanghai 200025 , China. Tel: + 86213469 6302; Fax: + 86215306 5329; E-mail: xu-happiness@ shsmu.edu.cn

Keywords: mitochondria; ASIC1a; MPT; oxidative cell death

Abbreviations: Aldh7a1, aldehyde dehydrogenase 7 family member a1; AMI, amiloride; ANT, adenine nucleotide translocase; ASIC1a, acid-sensing ion channel $1 \mathrm{a} ;\left[\mathrm{Ca}^{2+}\right]_{\mathrm{em}}$, extramitochondrial $\mathrm{Ca}^{2+}$ concentrations; $\mathrm{CRC}, \mathrm{Ca}^{2+}$ retention capacity; CsA, cyclosporin A; CTB, Cell-Titer Blue; CypD, cyclophilin D; Cyt C, cytochrome $c$; DNP, dinitrophenol; $\Delta \Psi_{\mathrm{m}}$, mitochondrial membrane potential; GAPDH, glyceraldehyde-3-phosphate dehydrogenase; Gpd2, glycerol-3-phosphate dehydrogenase 2; Hibch, 3-hydroxyisobutyryl-CoA hydrolase; $\mathrm{H}_{2} \mathrm{O}_{2}$, hydrogen peroxide; $\mathrm{MCU}$, mitochondrial $\mathrm{Ca}^{2}+$ uniporter; Mito-DsRed, mitochondrion-targeting red fluorescent protein; MPT, mitochondrial permeability transition; mtASIC1a, mitochondrial ASIC1a; MTCO2, cytochrome $c$ oxidase subunit 2; Mterfd2, mitochondria transcription termination factor domain containing 2; PcTX1, psalmotoxin 1; PDI, protein disulfide isomerase; PI, propidium iodide; Pick1, protein interacting with protein kinase C 1; PIN1peptidylprolyl cis/trans isomerase NIMA-interacting 1; ROS, reactive oxygen species; SIc25a25, solute carrier family 25 member 25; TMRM, tetramethylrhodamine methylester; VDAC, voltage-dependent anion channel

Received 10.11.12; revised 12.5.13; accepted 10.6.13; Edited by L Scorrano; published online 12.7.13
} 
During brain ischemia, the lack of oxygen and glucose causes mitochondrial dysfunction, disrupted intracellular $\mathrm{Ca}^{2+}$ homeostasis, increased reactive oxygen species (ROS) production and decreased ATP levels. These conditions increase mitochondrial susceptibility to MPT. ${ }^{10,13,14,16}$ Upon reperfusion, the MPT pores finally open, leading to ischemic/ reperfusion neuronal death. Moreover, deletion of cyclophilin $\mathrm{D}(\mathrm{CypD})$, a key regulator of the MPT pore, effectively rescued the ischemic damage. ${ }^{17}$ Although the pathophysiological importance of MPT has been extensively described in vivo and in vitro, its structural components still remain largely unknown. ${ }^{16,18-21}$ Recently, $F_{0} F_{1}$-ATP synthase was reported to form MPT pores. ${ }^{21}$

In this study, we show that intracellularly expressed ASIC1a proteins are localized in mitochondria of mouse cortical neurons and physically associated with adenine nucleotide translocase (ANT), a mitochondrial inner membrane protein previously suggested by some investigators to be part of the MPT pore. ${ }^{20,22}$ Moreover, brain mitochondria isolated from $\mathrm{ASIC} \mathrm{a}^{-/-}$mice exhibit significantly enhanced $\mathrm{Ca}^{2+}$ retention capacity $(\mathrm{CRC})$ and mitochondrial $\mathrm{Ca}^{2+}$ uptake rate. Neurons from $\mathrm{ASIC} 1 \mathrm{a}-n u l l$ mice are more resistant to hydrogen peroxide $\left(\mathrm{H}_{2} \mathrm{O}_{2}\right)$-induced cytochrome $c$ (Cyt $\mathrm{C}$ ) release and inner mitochondrial membrane depolarization than that from wild-type (WT) mice. Moreover, $\mathrm{H}_{2} \mathrm{O}_{2}$-induced neuronal death, which is MPT dependent, is reduced in $\mathrm{ASIC1a}^{-/-}$neurons. These results suggest an impaired
MPT function in $A S I C 1 a^{-/-}$mice. In addition, increased mitochondrial size and ROS levels are observed in the brain of $A S I C 1 a^{-1-}$ mice. Using two-dimensional difference gel electrophoresis followed by mass spectrometry (MS) analysis, we found marked changes ( $>2$-fold) in the levels of seven mitochondrial proteins in $A S I C 1 a^{-/-}$brains, most of which are known to play important roles in ROS signaling pathways (Supplementary Information and Supplementary Figure 6). Together, our data suggest a novel role of mitochondrial localized ASIC1a in regulating MPT-dependent neuronal death, which represents a key event of brain injury associated with ischemic stroke and neurodegenerative diseases.

\section{Results}

ASIC1a gene deletion but not channel functional inhibition reduced $\mathrm{H}_{2} \mathrm{O}_{2}$-induced neuronal death. It is generally accepted that ASIC1a forms plasma membrane channels that mediate acidosis-induced neuronal death., 6 To determine the specificity of ASIC1a in mediating neuronal death induced by different causes, we compared effects of $\mathrm{H}_{2} \mathrm{O}_{2}$ in inducing death of cultured cortical neurons prepared from WT and ASIC1a-knockout mice., ${ }^{3,23}$ We found that ASIC1a gene deletion significantly protected neurons against $\mathrm{H}_{2} \mathrm{O}_{2}$-induced cell death (Figure 1). The protective effect of ASIC1a gene deletion was seen with 10 and $50 \mu \mathrm{M} \mathrm{H}_{2} \mathrm{O}_{2}$ and treatment of 8 and $20 \mathrm{~h}$ but not with lower $\mathrm{H}_{2} \mathrm{O}_{2}$ concentration
A
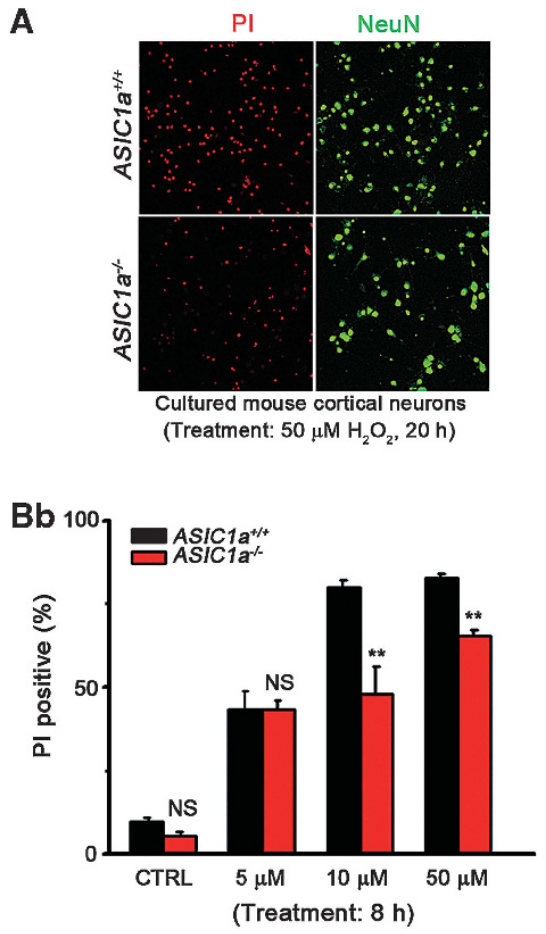

$\mathrm{Ba}$

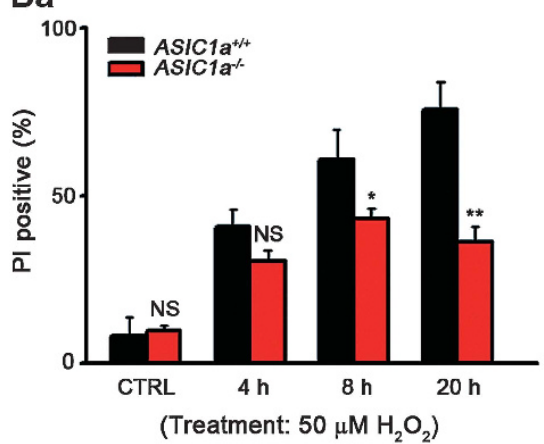

C

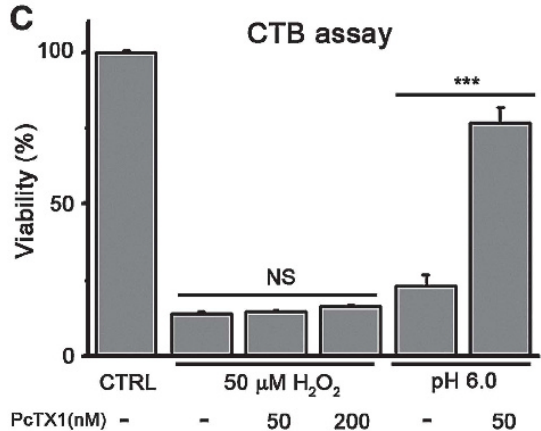

Figure $1 \mathrm{ASIC1} \mathrm{a}^{-/-}$neurons resisted oxidative stress-triggered death. (A) Neuronal death induced by the treatment of $50 \mu \mathrm{M} \mathrm{H}_{2} \mathrm{O}_{2}$ for $20 \mathrm{~h}$ of cultured cortical neurons from $\mathrm{ASICla}^{+/+}$(upper images) and $\mathrm{ASIC1a}^{-1-}$ (lower images) mice. Dead cells were labeled by staining with $\mathrm{PI}$ (red). Neurons were labeled by NeuN (green). (B) Summary data for PI-positive neurons in cultures treated with $50 \mu \mathrm{M} \mathrm{H}_{2} \mathrm{O}_{2}$ for different times (a) or with different concentrations of $\mathrm{H}_{2} \mathrm{O}_{2}$ for $8 \mathrm{~h}$ (b). ASIC1a ${ }^{-/-}$neurons (red bars) were more resistant to neuronal death than $\mathrm{ASIC1a}^{+/+}$ones (black bars), especially with longer treatment (a) and higher doses of $\mathrm{H}_{2} \mathrm{O}_{2}$ (b, $>200$ neurons were monitored in each treatment group). (C) Viability of neurons treated with $50 \mu \mathrm{M} \mathrm{H}_{2} \mathrm{O}_{2}$ or pH 6.0, determined using CTB assay. PcTX1 significantly inhibited acidosis-induced death but failed to rescue $\mathrm{H}_{2} \mathrm{O}_{2}$-induced neuronal death $\left(n=3-4,{ }^{\star} P<0.05\right.$, ${ }^{\star *} P<0.01,{ }^{* \star}{ }^{*} P<0.001$, NS, no statistical significance, by unpaired $t$-test; data are means \pm S.E.M. for all bar graphs) 
or shorter treatment (Figures 1A, a and b). To our surprise, however, the ASIC1a channel-specific inhibitor, psalmotoxin 1 (PcTX1) (50 and $200 \mathrm{nM}$ ), failed to rescue the $\mathrm{H}_{2} \mathrm{O}_{2}$ induced death, although it protected the cells from acid $(\mathrm{pH}$ 6.0)-induced death (Figure 1c). It is unlikely that $\mathrm{H}_{2} \mathrm{O}_{2}$ triggers channel activity of $\mathrm{ASIC} 1 \mathrm{a}$ as neither ASIC1a channels were directly activated by $\mathrm{H}_{2} \mathrm{O}_{2}{ }^{24}$ nor $\mathrm{H}_{2} \mathrm{O}_{2}$ $(50 \mu \mathrm{M})$ treatment caused any detectable extracellular acidification that could lead to ASIC1a activation (data not shown). In contrary, $\mathrm{H}_{2} \mathrm{O}_{2}$ treatment actually reduced the proportion of surface ASIC1a channels and therefore suppressed $\mathrm{H}^{+}$-induced currents. ${ }^{24}$ The above data thus suggest that $A S I C 1 a$ proteins participate in $\mathrm{H}_{2} \mathrm{O}_{2}$-induced neuronal death but in a manner that is independent of their plasma membrane ASIC1a channels.

ASIC1a gene deletion impaired MPT in mouse cortical neurons. $\mathrm{H}_{2} \mathrm{O}_{2}$-induced cell death is dependent on MPT, ${ }^{18,19}$ which is characterized by the opening of MPT pores, leading to mitochondrial membrane depolarization, mitochondrial swelling, rupture of the outer mitochondrial membrane and Cyt C release. ${ }^{14,15,25,26}$ The above finding promoted us to examine whether ASIC1a gene deletion affected MPT in mouse cortical neurons. The activity of MPT affects the ability of mitochondria to take up $\mathrm{Ca}^{2+}$ because mitochondrial $\mathrm{Ca}^{2+}$ overload provokes opening of MPT pores. $^{16,20,27}$ To examine whether ASIC1a gene deletion affected MPT, we first compared the CRC of mitochondria isolated from $\mathrm{ASIC} \mathrm{a}^{+/+}$and $\mathrm{ASIC1a^{-/- }}$ mouse brains. To the mitochondrial suspension, aliquots of $\mathrm{a} \mathrm{Ca}^{2+}$ solution were added in the presence of the substrates for complex I (glutamate and malate), and CRC was determined by monitoring changes in extramitochondrial $\mathrm{Ca}^{2+}$ concentrations $\left(\left[\mathrm{Ca}^{2+}\right]_{\mathrm{em}}\right)$ using Calcium Green-5N. We found a significant increase in CRC of $A S I C 1 a^{-/}$mitochondria compared with that of the WT mitochondria (Figures $2 a$ and b). Upon addition of the $\mathrm{Ca}^{2+}$ solution to mitochondria from ASIC1a ${ }^{-/-}$mice, the $\left[\mathrm{Ca}^{2+}\right]_{\mathrm{em}}$ returned to the basal level more rapidly, with the $50 \%$ recovery time being significantly shorter than that in mitochondria from WT mice (statistics of the first five peaks; Figures $2 a$ and $c$ ), suggesting an accelerated mitochondrial $\mathrm{Ca}^{2+}$ uptake rate because of the ASIC1a gene deletion. However, these effects were not reproduced by the treatment of ASIC1a inhibitors, amiloride (AMI) and PCTX1, on WT mitochondria. Neither drug enhanced the CRC (Figure $2 \mathrm{~b}$ ) or accelerated $\mathrm{Ca}^{2+}$ uptake rate of WT mitochondria (Supplementary Figure 1a), which is consistent with the lack of effect of PcTX1 on $\mathrm{H}_{2} \mathrm{O}_{2}$-induced death (Figure 1c).

We then used $250 \mu \mathrm{M} \mathrm{CaCl} \mathrm{Ca}_{2}$ to induce swelling of mitochondria isolated from mouse brains ${ }^{19}$ and observed a significant decrease in swelling rate of $A S I C 1 a^{-/-}$mitochondria compared with that of the WT ones (Figure 2d). To examine changes of mitochondrial membrane potential $\left(\Delta \Psi_{\mathrm{m}}\right)$ in response to $100 \mu \mathrm{M} \mathrm{H} \mathrm{H}_{2}$, we loaded cultured cortical neurons with tetramethylrhodamine methylester (TMRM). $\mathrm{H}_{2} \mathrm{O}_{2}$ caused an immediate reduction of $\Delta \Psi_{\mathrm{m}}$ in WT neurons (Figure 2e). However, for ASIC1a ${ }^{-/-}$neurons, the change was dramatically delayed, and an obvious decrease in $\Delta \Psi_{\mathrm{m}}$ was only observed $\sim 8 \mathrm{~min}$ after application of $\mathrm{H}_{2} \mathrm{O}_{2}$
(Figure 2e). Consistent with ASIC1a channel function not being involved in this process, PcTX1 failed to rescue the $\mathrm{H}_{2} \mathrm{O}_{2}$-induced loss of $\Delta \Psi_{\mathrm{m}}$ in WT neurons (Figure 2e).

To detect MPT pore opening, we employed the calcein$\mathrm{CoCl}_{2}$ bleaching assay. ${ }^{14} \mathrm{~A}$ treatment with $5 \mu \mathrm{M}$ ionomycin significantly reduced calcein fluorescence in cultured mouse cortical neurons (Supplementary Figure 1b). In neurons infected with a lentivirus vector, a treatment with $0.5 \mathrm{mM}$ $\mathrm{H}_{2} \mathrm{O}_{2}$ reduced calcein fluorescence, which was fully blocked by $5 \mu \mathrm{M}$ cyclosporin $\mathrm{A}$ (CsA) (Figures $2 \mathrm{f}$ and g). Importantly, knocking down the expression of endogenous ASIC1a with lentivirus-based shRNA (Figure 2g, upper panel) in cultured neurons also prevented the $\mathrm{H}_{2} \mathrm{O}_{2}$-induced calcein fluorescence loss (Figures $2 f$ and $g$ ), although it had no effect on the $5 \mu \mathrm{M}$ ionomycin-induced bleaching (Supplementary Figure 1b). These results suggest that ASIC1a is involved in regulating MPT pore opening.

Finally, we measured the amount of Cyt $\mathrm{C}$ released from mitochondria isolated from the brains of $A S I C 1 a^{-/-}$and WT littermates in response to $\mathrm{H}_{2} \mathrm{O}_{2}$ or $\mathrm{CaCl}_{2}$. In WT mitochondria, $\mathrm{H}_{2} \mathrm{O}_{2}$-induced Cyt $\mathrm{C}$ release was concentration and time dependent, but this effect was largely attenuated in $\mathrm{ASIC1a}^{-/-}$mitochondria (Figure 2h, upper and middle panels). Likewise, the $\mathrm{Ca}^{2+}$-induced Cyt $\mathrm{C}$ release was also reduced in $A S I C 1 a^{-/-}$mitochondria (Figure $2 \mathrm{~h}$, lower panel). Consistently, we found that shRNA knockdown of endogenous ASIC1a in WT neurons inhibited Cyt $C$ release induced by a low $(1 \mathrm{mM})$ but not a high $(10 \mathrm{mM})$ concentration of $\mathrm{H}_{2} \mathrm{O}_{2}$ in intact neurons (Figure 2i). Moreover, shRNA knockdown of endogenous ASIC1a partially, but significantly, rescued neurons from death induced by $\mathrm{Ca}^{2+}$ overload following the treatment with $5 \mu \mathrm{M}$ thapsigargin or $1 \mu \mathrm{M}$ A23187 (Figure 2j). Taken together, these data demonstrate that ASIC1a gene deletion impairs MPT.

Association of ASIC1a with ANT. Although MPT contributes to many neuronal diseases, the components of MPT pores remain largely undefined. ${ }^{18-21}$ Previous findings showed that CypD is an important regulator of MPT pores. $^{20,21}$ Importantly, because of the impaired MPT, CypD-deficient mice displayed a strong resistance against brain ischemic damage and motor neurons degeneration, ${ }^{17,20}$ reminiscent of the ASIC1a-deficient mice. ${ }^{5,6}$ Therefore, we tested the hypothesis that ASIC1a is a regulator (or even a structural component) of the MPT pore, presumably through association with CypD. However, co-immunoprecipitation (IP) using purified mitochondrial lysates from the mouse brain failed to reveal any physical interaction between ASIC1a and CypD (Figure 3a). Instead, we found that ASIC1a was physically associated with ANT, but not with voltage-dependent anion channel (VDAC), in the mitochondria (Figure 3a).

To rule out the possibility of false positives caused by nonspecific binding to the anti-ASIC1a antibody, we transfected EGFP-ASIC1a into human embryonic kidney 293 (HEK 293) cells and used anti-GFP antibody to reperform the co-IP assay. All proteins copurified with the anti-GFP antibody were subjected to SDS gel electrophoresis and visualized by Coomassie blue staining (Figure $3 \mathrm{Ba}$ ). Bands that were present in the GFP lane but not in the negative control IgG 

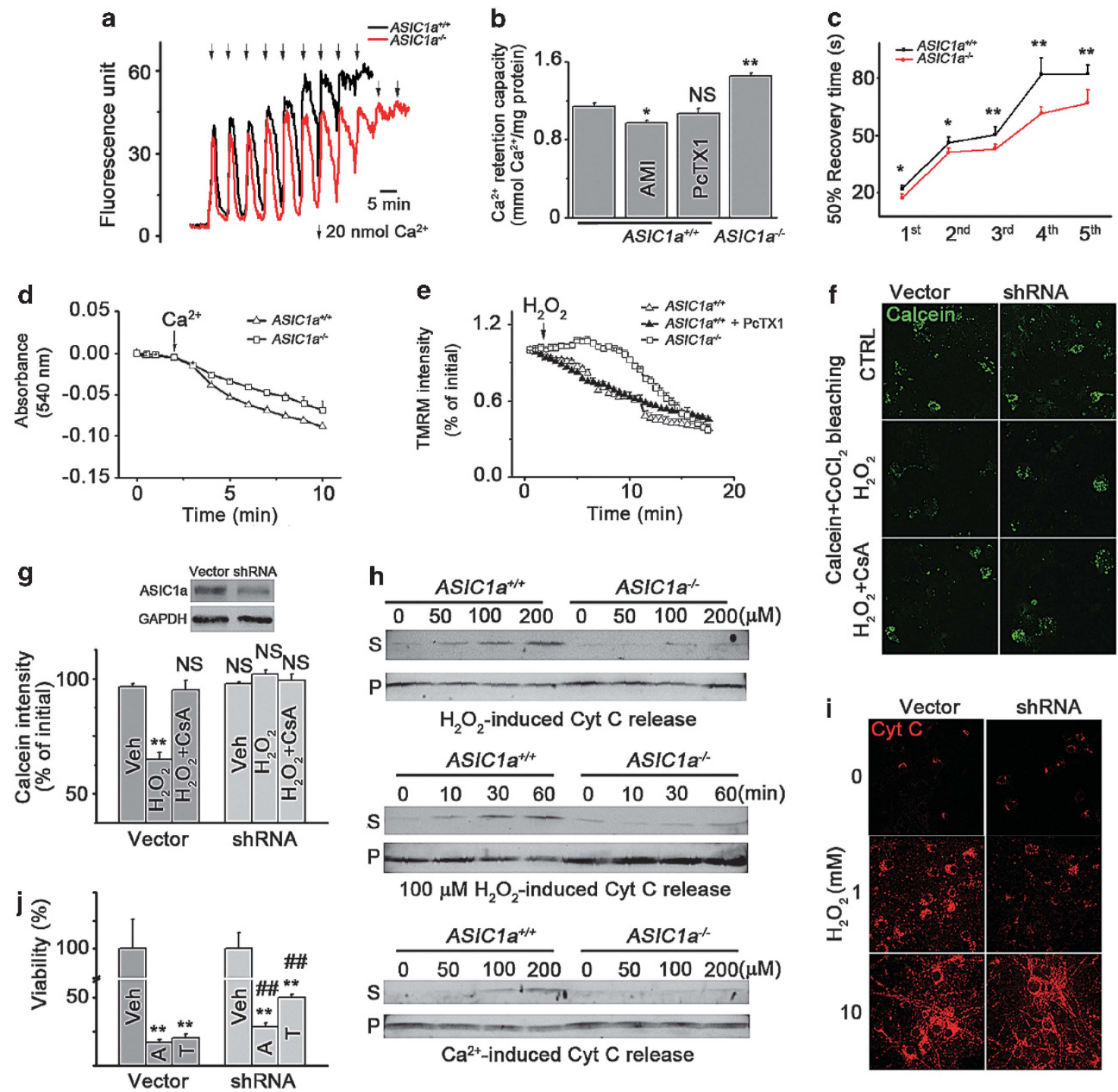

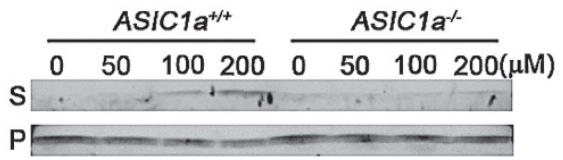

$\mathrm{Ca}^{2+}$-induced Cyt $\mathrm{C}$ release

Figure 2 MPT is impaired in mitochondria of $A S I C 1 a^{-/-}$neurons. (a) Representative traces of $\mathrm{Ca}^{2+}$ uptake by isolated mitochondria from $A S I C 1 a^{+/+}$(black trace) and $A S I C 1 a^{-1-}$ brains (red trace). (b) $\mathrm{Ca}^{2+}$ retention capacity of indicated groups $\left(n=16\right.$ for $A S I C 1 a^{+/+}$control, $n=11$ for $A S I C 1 a^{-1-}, n=4$ for $A S I C 1 a^{+/+} \mathrm{AMI}_{\text {and }}$ PcTX1 groups; ${ }^{*} P<0.05,{ }^{* *} P<0.01$, NS, no statistical significance, by unpaired $t$-test). (c) Fifty per cent recovery time of extramitochondrial $\mathrm{Ca}^{2+}$ (first five peaks in panel a were calculated, $n=8-11,{ }^{*} P<0.05,{ }^{* *} P<0.01$, by unpaired $t$-test). (d) Time courses of $\mathrm{Ca}^{2+}$-induced swelling of isolated brain mitochondria from $A S I C 1 a^{+/+}$(triangles) and $\mathrm{ASIC1a}^{-1-}$ (squares) mice. Data are means \pm S.E.M. of four experiments. (e) Time courses of $\Delta \Psi_{\mathrm{m}}$ loss induced by $100 \mu \mathrm{M} \mathrm{H}_{2} \mathrm{O}_{2}$ in cultured cortical neurons from $\mathrm{ASIC1a}^{+/+}$(open triangles) and ASIC1a ${ }^{-/-}$(open squares) mice. In ASIC1a ${ }^{+/+}$neurons, $200 \mathrm{nM}$ PcTX1 (filled triangles) failed to affect the $\Delta \Psi_{\mathrm{m}}$ loss. Data are means \pm S.E.M. of four experiments. ( $\mathbf{f}$ and $\mathbf{g}$ ) Representative images of calcein- $\mathrm{CoCl}_{2}$ bleaching assays ( $\mathbf{f}$ ) and the summary data for relative calcein intensities in cells treated with $\mathrm{H}_{2} \mathrm{O}_{2}(1 \mathrm{mM})$ or $\mathrm{H}_{2} \mathrm{O}_{2}+\mathrm{CsA}(10 \mu \mathrm{M})$ for $1 \mathrm{~h}(\mathbf{g}) ; n=3$ for each group. Inset shows shRNA-knockdown efficiency as determined by western blot. ${ }^{* *} P<0.01$, NS, no statistical significance, by unpaired $t$-test. (h) $\mathrm{Cyt} \mathrm{C}$ release induced by $\mathrm{H}_{2} \mathrm{O}_{2}$ (upper and middle panels) and $\mathrm{Ca}^{2+}$ (bottom panel) from brain mitochondria isolated from $\mathrm{ASICla}^{+/+}$and $\mathrm{ASICla}^{-/-}$mice. Mitochondria were incubated with different concentrations of $\mathrm{H}_{2} \mathrm{O}_{2}$ (upper panel) or $\mathrm{Ca}^{2+}$ (lower panel) for 60 min or with $100 \mu \mathrm{M} \mathrm{H}_{2} \mathrm{O}_{2}$ for different time periods (middle panel) as indicated (S, supernatant; $P$, pellet). (i) $\mathrm{H}_{2} \mathrm{O}_{2}$-induced Cyt $\mathrm{C}$ release in whole neurons. (j) shRNA of ASIC1a significantly reduced neuronal death caused by $5 \mu \mathrm{M}$ thapsigargin (T) or $1 \mu \mathrm{M}$ A23187 (A) ( $n=4$ for each group, ${ }^{* *} P<0.01$, compared with Veh, ${ }^{\# \#} P<0.01$, compared between the groups treated with the same drugs, by unpaired $t$-test; data are means \pm S.E.M. for all bar graphs)

lane were considered as ASIC1a-binding proteins (Figure $3 \mathrm{Ba}$ ). MS analysis of the unique $\sim 30 \mathrm{kDa}$ band (indicated in Figure $3 \mathrm{Ba}$ ) revealed peptide fragments consistent with that of ANT2 (Figure 3Bb; Supplementary Figure 2 and Supplementary Table 1). These data suggest that ASIC1a is physically associated with ANT, a possible regulator of the MPT pore yet under debating. ${ }^{20,21}$
Localization of ASIC1a proteins in mouse mitochondria. Recent evidence suggested an intracellular perinuclear location of ASIC1a in both transfected Chinese hamster ovary $(\mathrm{CHO})$ cells and cultured mouse cortical neurons. ${ }^{8,28}$ The association between ASIC1a and ANT suggested that some intracellular ASIC1a proteins might be localized to mitochondria. To verify the mitochondrial localization of 

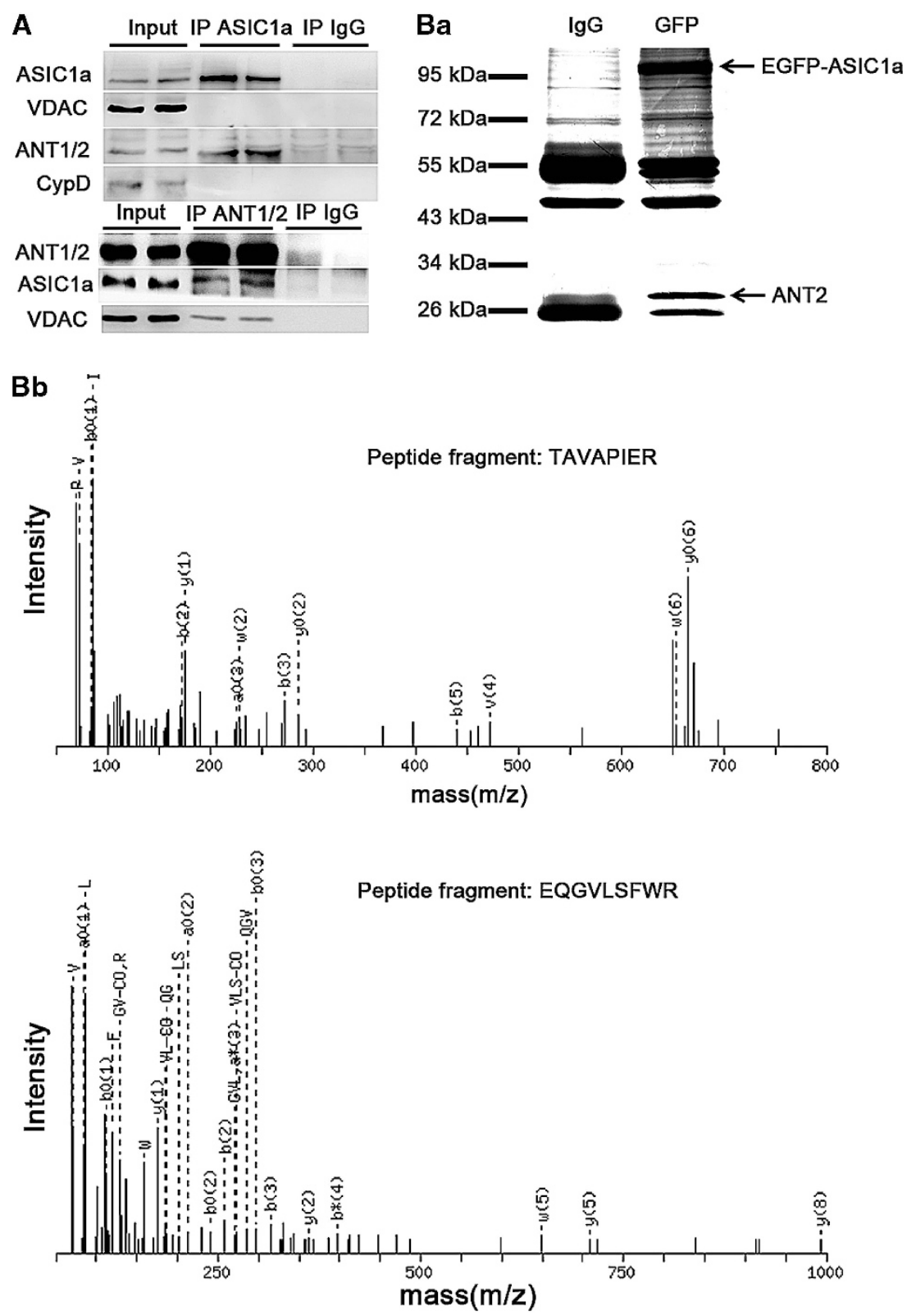

Figure 3 ASIC1a is physically associated with ANT. (A) ANT was detected in the immunoprecipitants by the anti-ASIC1a antibody (upper panel), and ASIC1a was detected in the immunoprecipitants by the anti-ANT1/2 antibody (lower panel) of isolated mouse brain mitochondrial fractions. (B) Identification of ASIC1a-associated proteins from HEK 293 cells expressing EGFP-tagged ASIC1a by IP using the anti-GFP antibody. A protein band of $\sim 30 \mathrm{kDa}$ (indicated by the lower arrow in panel b1) was subjected to MS analysis (b) and identified to be ANT2 (b, specific peptide fragments of ANT2, TAVAPIER and EQGVLSFWR; see Supplementary Figure 2 and Supplementary Table 1 for details)

ASIC1a, we first made crude cellular fractionations from mouse cortices by sucrose gradient centrifugation at different speeds. ASIC1a was found to be present in all fractions in which the mitochondrial proteins VDAC and Cyt $C$ were enriched (Figure 4a). Consistent with previous findings, ${ }^{8,28}$ we noticed that ASIC1a was also present in the endoplasmic reticulum (ER) fractions, indicated by the enrichment of protein disulfide isomerase (PDI) (Figure 4a).

To further ascertain the mitochondrial expression of ASIC1a, we coexpressed mitochondrion-targeting red fluorescent protein (Mito-DsRed) and EGFP-ASIC1a in cortical neurons and demonstrated that most of mitochondria were positive for EGFP-ASIC1a signals (Figure $4 \mathrm{~b}$ and Supplementary Figure 4). We next isolated mitochondria from mouse cortices using Percoll gradient centrifugation ${ }^{29}$ and found a significant enrichment of ASIC1a in the mitochondrial fraction (Figure 4c). Importantly, the ASIC1a-positive signals were only detected in cortical lysates and mitochondrial fractions of the WT mice but not that of $A S I C 1 a^{-/-}$mice (Figure 4d), validating the specificity of the antibody and supporting the specific expression of ASIC1a in mouse cortical neuron mitochondria. To examine whether ASIC1a 

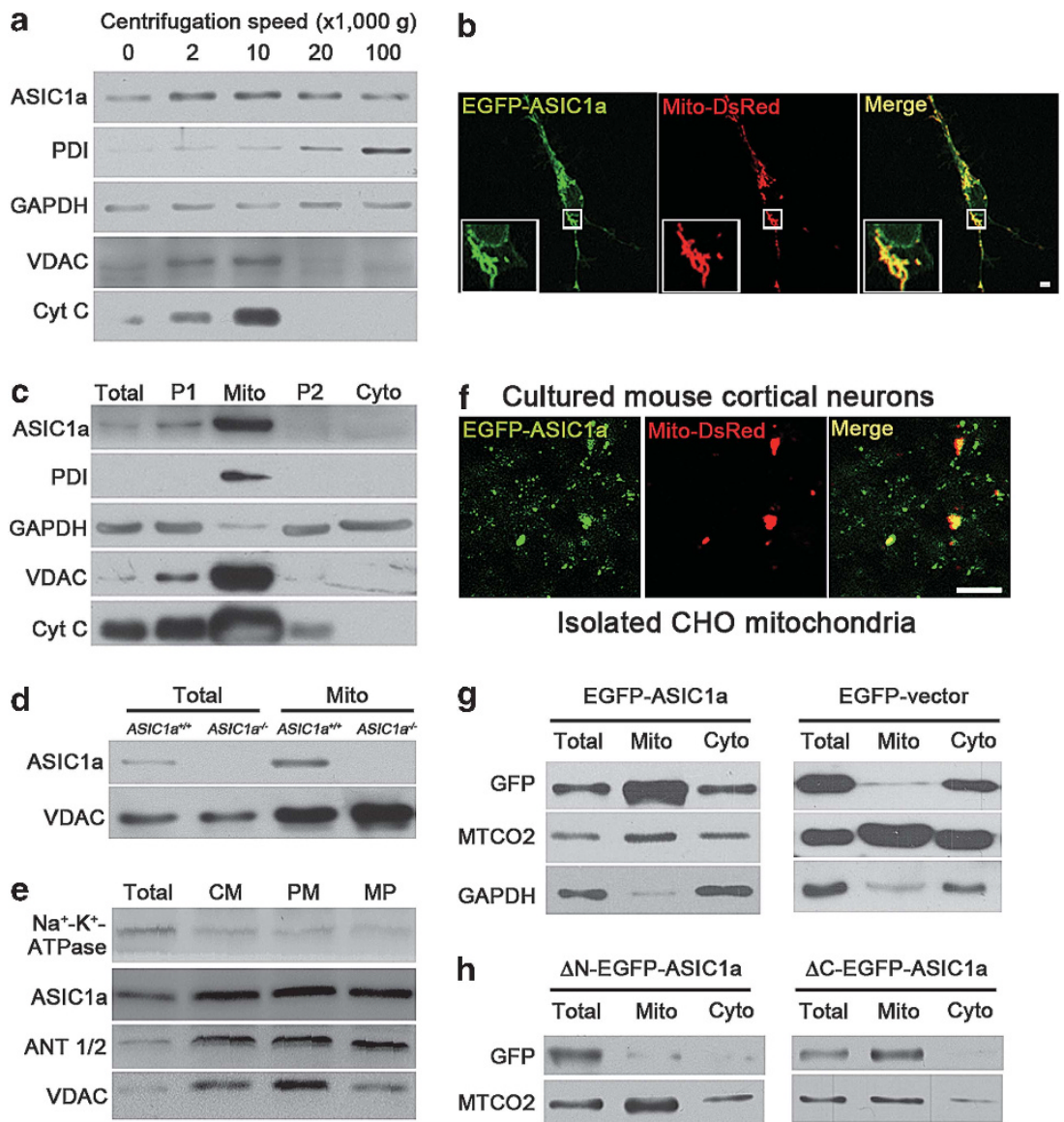

Isolated $\mathrm{CHO}$ mitochondria
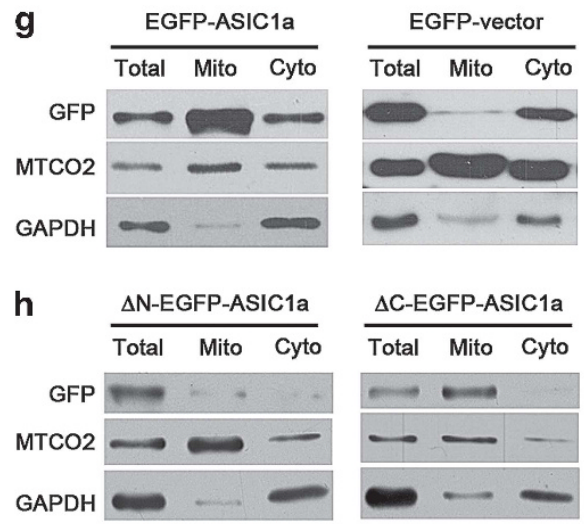

Transfected $\mathrm{CHO}$ cells

Figure 4 ASIC1a is expressed in mitochondria of mouse cortical neurons. (a) Presence of ASIC1a and organelle markers (PDI for ER, glyceraldehyde-3-phosphate dehydrogenase (GAPDH) for cytosol, and VDAC and Cyt C for mitochondria) in cell fractions of mouse cortex separated by centrifugations at different speeds $(\times 1000 \times g)$ as indicated. (b) Fluorescence images of a cultured mouse cortical neuron co-transfected with EGFP-ASIC1a (green) and Mito-DsRed (red). Insets, enlarged images for the boxed region. Scale bar $=10 \mu \mathrm{m}$. See Supplementary Figure 4 for details of colocalization. (c) Presence of ASIC1a and organelle markers in mitochondrial preparations by Percoll gradient centrifugation. Total, whole cortex lysate; P1, crude nuclear fractions; Mito, mitochondrial fractions; P2, light membrane fractions; Cyto, cytosolic fractions. (d) Presence of ASIC1a and VDAC in total lysates (total) and mitochondrial fractions (Mito) prepared from brains of SSIC1a $^{+/+}$and ASIC1a ${ }^{-/-}$mice. (e) Presence of ASIC1a and ANT1/2 in mitoplast fractions (CM, crude mitochondrial fractions; PM, purified mitochondrial fractions; MP, mitoplast fractions). (f) Fluorescence images of crude mitochondria isolated from CHO cells expressing EGFP-ASIC1a (green) and Mito-DsRed (red). Scale bar $=5 \mu \mathrm{m}$. ( $\mathrm{g}$ and $\mathbf{h}$ ) Detection of GFP signals in total, mitochondrial (Mito) and cytosolic (Cyto) fractions of CHO cells that were separately transfected with GFP-ASIC1a or EGFP-vector (g) and $\triangle \mathrm{N}$-EGFP-ASIC1a or $\triangle \mathrm{C}$-EGFP-ASIC1a (h). Cytochrome $c$ oxidase subunit 2 (MTCO2) was used as a marker for mitochondria

localized in mitochondrial outer or inner membrane, we prepared mitoplast fractions and found that ASIC1a was present with a similar expression pattern as the mitochondrial inner membrane protein ANT but not the mitochondrial outer membrane protein VDAC (Figure $4 \mathrm{e} ; \mathrm{Na}^{+}-\mathrm{K}^{+}$-ATPase was used as an indicator of plasma membrane components).

$\mathrm{N}$-terminus regulated mitochondrial localization of ASIC1a. A previous study suggested that transfected ASIC1a was mainly localized to the $\mathrm{ER}$ in $\mathrm{CHO}$ cells. ${ }^{28}$ However, ER and mitochondria physically interact and share a similar perinuclear distribution pattern in the cell, ${ }^{30,31}$ making it difficult to accurately assign the location of ASIC1a between the two tightly associated organelles in intact cells. To overcome this limitation, we isolated mitochondria from $\mathrm{CHO}$ cells that coexpressed EGFP-ASIC1a and Mito-DsRed.
Consistent with our finding in mouse cortical neurons, EGFP signals were observed in isolated mitochondria labeled with Mito-DsRed (Figure 4f). In addition, the GFP antibody revealed an enrichment of the expressed EGFP-ASIC1a, but not the non-fused EGFP, in the mitochondrial fraction (Figure $4 \mathrm{~g}$ ). In addition, we prepared mitochondrial fractions from HEK 293 cells transfected with EGFP-ASIC1a. Bands that were present in the EGFP-ASIC1a lane but not in the negative control vector lane were considered as EGFPASIC1a proteins (Supplementary Figure 3b1). MS analysis of the unique $\sim 95 \mathrm{kDa}$ band (indicated in Supplementary Figure $3 b 1$ ) revealed peptide fragments consistent with that of ASIC1a (Supplementary Figures 3b2, 5-1 and 5-2).

Moreover, although specific amino-acid sequence motifs have been described for certain proteins to import and target to mitochondria, ${ }^{32}$ no classical mitochondria-targeting 
sequence is present in ASIC1a. However, deletion of the $\mathrm{N}$ terminus (but not $\mathrm{C}$ terminus) of ASIC1a greatly reduced its mitochondrial expression (Figure 4h), suggesting that residues in the $\mathrm{N}$ terminus are essential for the mitochondrial localization of ASIC1a. Therefore, the above data clearly show that ASIC1a is localized in mitochondria; such localization likely contributes to the physiological and pathological functions of mitochondria.

Deletion of ASIC1a gene increased mitochondrial size of cortical neurons as well as oxidative stress levels in mouse brain. Next, we examined possible functional changes of mitochondria in $A S I C 1 a^{-/-}$neurons. As an ion channel, mitochondrial ASIC1a (mtASIC1a) could contribute to matrix osmolarity, which plays an important role in regulating mitochondrial volume. ${ }^{15}$ Thus, we measured the density and sizes of mitochondria in cortical neurons from $\mathrm{ASIC} \mathrm{a}^{-/-}$and WT animals based on electron microscopic (EM) images. Although the mean density of mitochondria remained unchanged, the mean size was moderately increased in $\mathrm{ASIC1a}^{-/-}$mice (Figures $5 \mathrm{a}-\mathrm{C}$ ). Distribution plots revealed a smaller proportion of mitochondria of $<0.2 \mu \mathrm{m}^{2}$ and a larger proportion of mitochondria of $>0.4 \mu \mathrm{m}^{2}$ in ASIC1a $^{-/-}$neurons (Figure 5c).

Mitochondria are the key producer of ROS. ${ }^{26}$ Therefore, we measured protein carbonylation, a biomarker of tissue ROS levels, ${ }^{33}$ in mouse brains using the 2,4-dinitrophenylhydrazine assay. We observed a much higher level of dinitrophenol (DNP) proteins in $A S I C 1 a^{-/-}$than in WT mouse cortices (Figure 5d), indicative of enhanced oxidative stress in ASIC1a ${ }^{-1-}$ mouse brain. We then used Mitosox to indicate the ROS produced directly from mitochondria and found a significantly higher Mitosox fluorescence in neurons infected with lentivirus of ASIC1a shRNA (Figure 5e). Moreover, treatment of cultured mouse cortical neurons with both 1 and $3 \mathrm{mM} \mathrm{H} \mathrm{H}_{2}$ for $3 \mathrm{~h}$ caused a significant intracellular ROS elevation in neurons infected with the control lentivirus (Figure 5f). However, with the ASIC1a shRNA lentivirus, the same concentrations of $\mathrm{H}_{2} \mathrm{O}_{2}$ failed to induce any detectable change in intracellular ROS levels (Figure 5f), suggesting that although the basal ROS level was higher in these neurons, they were resistant to $\mathrm{H}_{2} \mathrm{O}_{2}$-induced ROS elevation. These
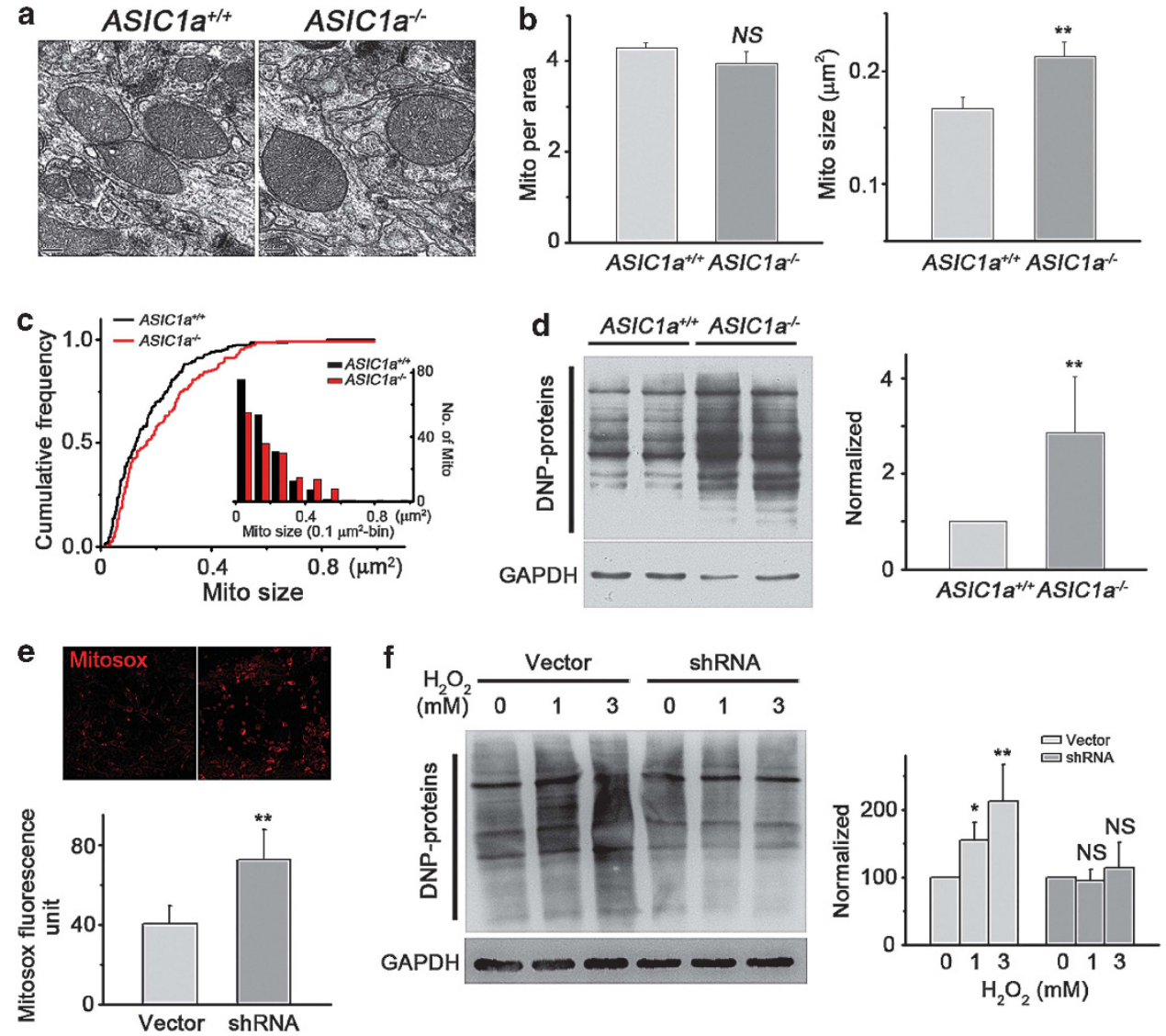

Figure 5 Deletion of ASIC1a gene increased mitochondrial size and caused a significant increase in oxidative stress in mouse brain. (a) Representative EM images of mitochondria in the brain of $A S I C 1 a^{+/+}$and $A S I C 1 a^{-/-}$mice. (b) Summary data on mitochondrial density (left panel) and size (right panel) determined using EM images ( $n=185$ for $\mathrm{ASIC1a}^{+/+}$mitochondria; $n=160$ for $A S I C 1 a^{-/-}$mitochondria; ${ }^{* *} P<0.01$, NS, no statistical significance, by unpaired $t$-test). (c) Cumulative distribution plots of mitochondrial size for the same data set shown in panel $\mathbf{b}$ (right panel). The numbers are also displayed at $0.1 \mu \mathrm{m}^{2}$ bins in the inset. (d) Detection of protein carbonylation in cortices of $\mathrm{ASIC1a}^{+/+}$and $\mathrm{ASIC1a}{ }^{-/-}$mice. A representative blot (left panel) and summary data from four experiments (right panel) are shown $\left(n=4,{ }^{* *} P<0.01\right.$, by unpaired t-test). (e) Increased Mitosox staining in neurons infected with control lentivirus (vector) or lentivirus for shRNA of mouse ASIC1a (upper panel, representative images; lower panel, summary data; $n=11$ for each group; ${ }^{* *} P<0.01$, by unpaired $t$-test). (f) Detection of protein carbonylation induced by indicated concentrations of $\mathrm{H}_{2} \mathrm{O}_{2}$ in cultured neurons infected with control virus and lentivirus for shRNA of ASIC1a. A representative blot (left panel) and summary data from four experiments (right panel) are shown $\left(n=4,{ }^{*} P<0.05,{ }^{*} P<0.01\right.$, NS, no statistical significance, by unpaired $t$-test; data are means \pm S.E.M. for all bar graphs) 
data revealed novel physiological functions of mtASIC1a in regulating mitochondrial volume and ROS production.

\section{Discussion}

In this study, we demonstrate that, besides acting as protongated channels on the plasma membrane, ASIC1a is also expressed in the mitochondria of mouse cortical neurons. The mtASIC1a is physically associated with a mitochondrial inner membrane protein, ANT. We show that $A S I C 1 a^{-1-}$ neurons exhibit impaired MPT function and are resistant to neuronal death induced by oxidative stress. Brain cells in the $A S I C 1 a^{-1-}$ mice also have enlarged mitochondria and enhanced ROS levels. Our findings reveal a novel subcellular localization and intracellular function of ASIC1a.

An increasing number of conventionally known plasma membrane ion channels and receptors, for example, large-conductance calcium- and voltage-activated potassium channels, ${ }^{15}$ the type- 1 cannabinoid receptor ${ }^{34}$ and $\mathrm{N}$-methyl$\mathrm{D}$-aspartate receptors, ${ }^{35}$ have been detected in mitochondria and demonstrated to regulate mitochondrial pathophysiological functions. However, how mitochondrial localized channels operate remains largely unknown. For mtASIC1a, it appears that despite the clear requirement for ASIC1a expression in the modulation of MPT, the ion channel function of ASIC1a may not be as critical because the channel inhibitors AMI and PcTX1 both failed to mimic the effect of ASIC1a gene deletion in increasing $\mathrm{CRC}$ and accelerating mitochondrial $\mathrm{Ca}^{2+}$ uptake rate (Figure $2 \mathrm{~b}$ and Supplementary Figure 1a). Moreover, as ASIC1a channels desensitize quickly and mitochondrial $\mathrm{Ca}^{2+}$ uptake is mainly mediated by the uniporter and exchangers, it is unlikely that proton-induced $\mathrm{mtASIC} 1 \mathrm{a}$ activation can give rise to sustained $\mathrm{Ca}^{2+}$ entry to activate MPT. There is no evidence that proton-activated ion channels are involved in the activation of MPT. This raises the possibility that mtASIC1a contributes to either the regulation (Figure 6a, upper left panel) or formation (Figure 6a, upper right panel) of MPT pores independent of its ion channel function. However, as MPT is ubiquitously present in all cells but ASIC1a has only been found in the CNS so far, ${ }^{1,36}$ the mtASIC1a most likely would only serve as an important regulator of MPT pores in cells of the CNS. Recently, $F_{0} F_{1}$-ATP synthase was reported to form MPT pores. ${ }^{21}$ Considering its proton-transporting function, it should be of interest to test whether a cross-talk between $\mathrm{F}_{0} \mathrm{~F}_{1}$-ATP synthase and mtASIC1a exists in CNS neurons (Figure 6a, bottom panel).

Alternatively, it is also possible that neither AMI nor PcTX1 can pass through the outer mitochondrial membrane for an
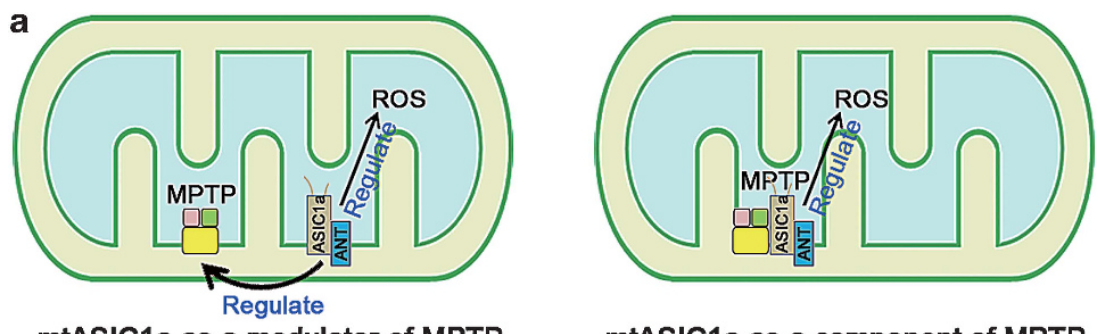

mtASIC1a as a modulator of MPTP

mtASIC1a as a component of MPTP
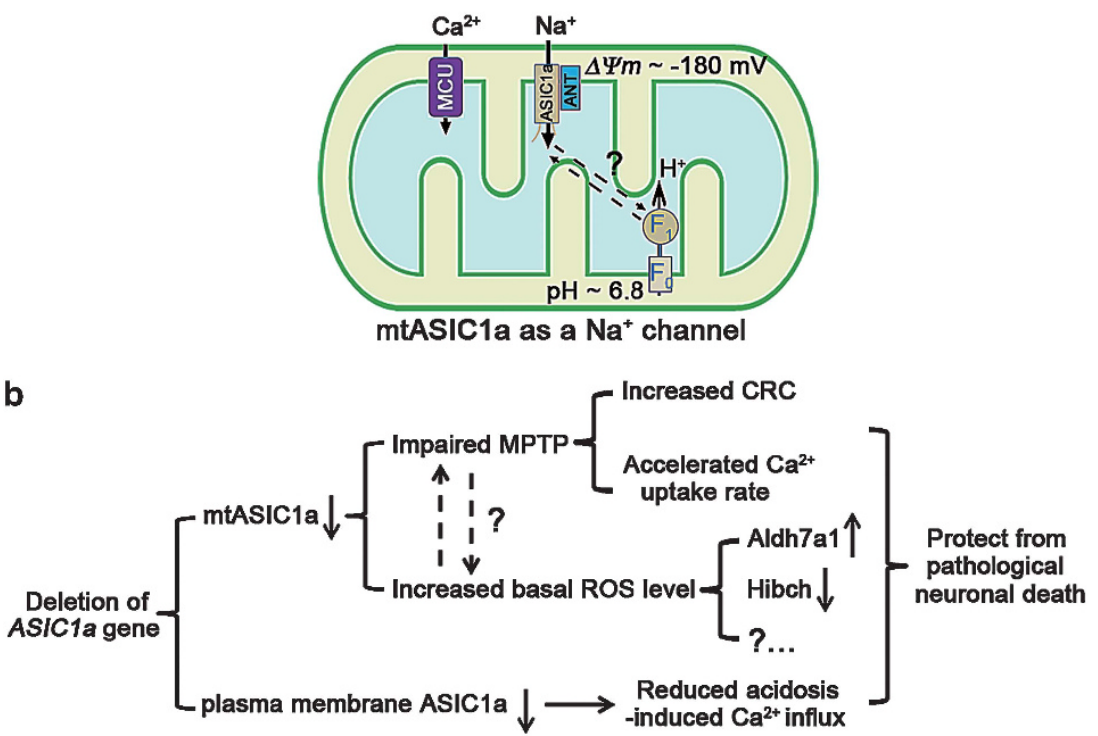

Figure 6 Schematics of possible mechanisms of action of ASIC1a in mitochondria. (a) (1) Nonconducting role(s) of mtASIC1a: mtASIC1a may function as one of the modulators of MPT pores (upper left panel); mtASIC1a may function as one of the components of MPT pores (upper right panel). (2) mtASIC1a may mediate Na ${ }^{+}$influx, reducing the driving force and counteracting MCU. (b) The protective effects of ASIC1a gene deletion in pathological neuronal death. ANT, adenine nucleotide translocase; $\mathrm{MCU}$, mitochondrial $\mathrm{Ca}^{2+}$ uniporter; MPTP, mitochondrial permeability transition pore, ROS, reactive oxygen species; $F_{0}, F_{0}$ portion of ATP synthase; $F_{1}, F_{1}$ portion of ATP synthase; $\Delta \Psi_{\mathrm{m}}$, mitochondrial membrane potential 
access to mtASIC1a located on the inner membrane. As $\mathrm{Na}^{+}$ is the main ion conducted by ASIC1a, the mtASIC1a may mediate $\mathrm{Na}^{+}$influx into mitochondrial matrix (Figure $6 \mathrm{a}$, bottom panel), a phenomenon that has been described in astrocytes and neurons under resting conditions. ${ }^{37}$ The matrix $\mathrm{Na}^{+}$concentration reached a mean value of $\sim 36 \mathrm{mM}$ during the mitochondrial $\mathrm{Na}^{+}$spiking, which was also accompanied with mitochondrial depolarization. ${ }^{37}$ As $\mathrm{pH}$ fluctuations occur at both the matrix and the intermembrane space of mitochon$\mathrm{dria}^{38}$ the mtASIC1a channel is subjected to activity changes no matter which orientation it adapts at the inner mitochondrial membrane. Because of the very negative potential and low $\mathrm{Na}^{+}$concentration in the matrix side, the opening of mtASIC1a should result in $\mathrm{Na}^{+}$influx and mitochondrial depolarization, which in turn could reduce the driving force for $\mathrm{Ca}^{2+}$ entry (Figure $6 \mathrm{a}$, bottom panel). It would be of interest in future experiments to test whether mtASIC1a can be activated by $\mathrm{pH}$ changes in either the matrix side or the intermembrane space, as well as the kinetics and duration of its activation, using direct mitochondrial electrophysiological recordings.

Accumulating evidence shows that ASIC1a contributes to cell death in a variety of neurological disorders, such as ischemic stroke, multiple sclerosis, Parkinson's disease

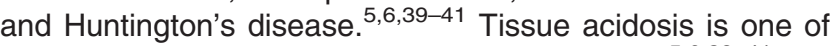
the common symptoms shared by these diseases ${ }^{5,6,39-41}$ and considered as the cause of ASIC1a-mediated neuronal damage. ${ }^{5,6,39-41}$ Notably, mitochondria play essential roles in all these diseases. ${ }^{10,14,26,42}$ Taken ischemic stroke as an example, ASIC1a gene deletion has been shown to protect against ischemic brain damage in the rodent focal ischemia/ reperfusion model, middle cerebral artery occlusion. ${ }^{5-7}$ Coincidently, the same model is also widely used in MPT-related studies because MPT undertakes the 'execution' function of cell demise in this model. ${ }^{10,14,17}$ Therefore, although speculative, plasma membrane ASIC1a (death initiator) and mtASIC1a (death executor) may function at different levels to regulate ischemic cell death, which may cooperatively explain the observed strong neuroprotective effect in ASIC1a-knockout mice (Figure 6b). ${ }^{10,13,15}$

It was reported that compared with WT mice, ASIC1adeficient mice had both a markedly reduced motor deficit and decreased axonal degeneration in a mouse model of experimental autoimmune encephalomyelitis despite the similar levels of CNS inflammation. ${ }^{39,43}$ Interestingly, ASIC1a was found only in the surface membrane of neuronal soma and dendrites but not that of axons. ${ }^{3,44}$ Perturbed intracellular $\mathrm{Ca}^{2+}$ homeostasis was considered as a major underlying cause of this disease. ${ }^{45}$ However, it is hard to imagine how somatodendritic localized ASIC1a channels, with a weak $\mathrm{Ca}^{2+}$ permeability, contribute to the degeneration of axons, where no ASIC1a channel is present. On the contrary, mitochondrial dysfunction (such as energy failure and alteration of mitochondrial ROS production) is generally accepted as a prominent cause of axonal degeneration in multiple sclerosis, and two inhibitors of MPT pore formation have been shown to delay disease onset and increase survival of amyotrophic lateral sclerosis mice. ${ }^{13,46}$ Because mitochondria (and presumably mtASIC1a) are distributed and functional in axons, ${ }^{13}$ our study provides an alternative explanation that the protection against axonal degeneration observed in ASIC1a-deficient mice may be due to reduced activity in MPT. Taken together, our findings suggest that, besides plasma membrane ASIC1a, mtASIC1a may also be a promising target for drug design and clinical therapy.

\section{Materials and Methods}

Primary culture of mouse cortical neurons. Primary cultures of mouse cortical neurons were prepared as described previously. ${ }^{7}$ The experimental protocols were approved by Animal Care and Use Committee of Shanghai Jiao Tong University School of Medicine and the Institutional Animal Care and Use Committee of Institute of Neuroscience, Shanghai, China. Briefly, postnatal day 1 C57BL/6 WT or $A S / C 1 a^{-1-}$ mice (with congenic C57BL/6 background) were anesthetized with halothane. Brains were removed rapidly and placed in ice-cold $\mathrm{Ca}^{2+}$ - and $\mathrm{Mg}^{2+}$-free phosphate-buffered saline (PBS). Tissues were dissected and incubated with $0.05 \%$ trypsin-EDTA for $15 \mathrm{~min}$ at $37^{\circ} \mathrm{C}$, followed by trituration with fire-polished glass pipettes, and plated in poly-D-lysine-coated $35-\mathrm{mm}$ culture dishes at a density of $1 \times 10^{6}$ cells per dish. Neurons were cultured with Neurobasal medium supplemented with B27 and maintained at $37^{\circ} \mathrm{C}$ in a humidified $5 \% \mathrm{CO}_{2}$ atmosphere incubator. Cultures were fed twice a week and used for all the assays 8-14 days after plating. Glial growth was suppressed by the addition of 5-fluoro-2-deoxyuridine $(20 \mu \mathrm{g} / \mathrm{ml}$; Sigma-Aldrich, St Louis, MO, USA) and uridine (20 $\mu \mathrm{g} / \mathrm{ml}$; Sigma-Aldrich).

shRNA of mouse ASIC1a. The shRNA was designed to target mouse ASIC1a with the sequence of CACC-G GACAT TCAGC AAGAT GAATA-TTCAA GAG-AT ATTCA TCTTG CTGAA TGTCC-TTTTT TG, and its effectiveness was tested by western blotting. The cultured mouse cortical neurons were infected with lentivirus for ASIC1a shRNA or a control lentivirus at DIV 7. Assays were performed $72 \mathrm{~h}$ after virus infection.

Mitochondrion isolation and analyses. Mouse cortical neuron mitochondria were isolated by homogenization followed by differential centrifugation. ${ }^{29}$ Briefly, mice were euthanized by decapitation. Brains were removed, and cortices were separated, minced and washed three times in isolation buffer (0.32 M sucrose, $1 \mathrm{mM}$ EDTA, $10 \mathrm{mM}$ Tris- $\mathrm{HCl}, \mathrm{pH}$ 7.4). The tissue was then homogenized in isolation buffer ( $10 \% \mathrm{w} / \mathrm{v})$ using a Dounce homogenizer with 12 strokes. The homogenate was diluted 1:1 with Percoll $(24 \%)$ in isolation buffer and centrifuged at $30700 \times g$ for $10 \mathrm{~min}$. The upper half was removed and diluted with isolation buffer (final concentration of Percoll is 12\%) and then homogenized again for four strokes and centrifuged at $30700 \times g$ for $10 \mathrm{~min}$. The lower part was mixed with the lower half obtained from the first centrifugation and layered on a Percoll step gradient (19 and $40 \%$ ). Then, it was centrifuged at $30700 \times g$ for $15 \mathrm{~min}$. The fraction between the two lower Percoll layers was collected, diluted $1: 4$ with isolation buffer and centrifuged at $16700 \times g$ for $10 \mathrm{~min}$. The resulting pellet was resuspended in $0.5 \mathrm{ml}$ bovine serum albumin $(10 \mathrm{mg} / \mathrm{ml})$ and centrifuged at $6900 \times g$ for $10 \mathrm{~min}$. Then, the pellet was resuspended in $200 \mathrm{ml}$ of isolation buffer. Similar protocol was used for isolation of mitochondria from $\mathrm{CHO}$ cells. Isolated mitochondria were assayed by western blotting and electron microscopy (data not shown) to evaluate the purity.

To remove the ER fractions, the above pellet was resuspended in a sucrosebased isolation buffer ( $0.21 \mathrm{M}$ sucrose, $70 \mathrm{mM}$ mannitol, $1 \mathrm{mM}$ EDTA, $1 \mathrm{mM}$ EGTA, $1.5 \mathrm{mM} \mathrm{MgCl}_{2}, 10 \mathrm{mM}$ HEPES, pH 7.4) and then centrifuged at $100000 \times \mathrm{g}$ for $1 \mathrm{~h}$. The pellet was collected as purified mitochondrial fractions.

To prepare mitoplast, the purified mitochondria were suspended in 10 volumes of a hypotonic buffer ( $10 \mathrm{mM}$ Tris base, $1 \mathrm{mM} \mathrm{EGTA}, \mathrm{pH} 7.4$ ), and digitonin was added to give a final concentration of $0.1 \%$. This mixture was incubated on ice for $45 \mathrm{~min}$. An equal volume of $150 \mathrm{mM} \mathrm{KCl}$ was then added, and the mixture was incubated for 2 min on ice before centrifugation at $18000 \times g$ for $20 \mathrm{~min}$. The pellet was collected as mitoplast. All centrifugation steps were carried out at $4^{\circ} \mathrm{C}$.

The CRC assay was performed in a reaction buffer $\left(125 \mathrm{mM} \mathrm{KCl}, 4 \mathrm{mM} \mathrm{K}_{2} \mathrm{HPO}_{4}\right.$, $1 \mathrm{mM} \mathrm{MgCl}_{2}, 20 \mathrm{mM}$ HEPES, $5 \mathrm{mM}$ glutamate, $5 \mathrm{mM}$ malate, $\mathrm{pH}$ 7.4) containing $1 \mu \mathrm{M}$ Calcium Green-5N salt in $100-\mu$ l volumes in wells of a 96-well plate. Fluorescence changes were measured in a SpectraMax Paradigm Multimode Microplate Reader (Molecular Devices, Sunnyvale, CA, USA), with the excitation wavelength of $506 \mathrm{~nm}$ and emission wavelength of $531 \mathrm{~nm}$. One-microliter aliquots of a $20 \mathrm{mM} \mathrm{CaCl}$ solution $\left(20 \mathrm{mM} \mathrm{CaCl}, 129 \mathrm{mM} \mathrm{KCl}, 1 \mathrm{mM} \mathrm{MgCl}_{2}, 20 \mathrm{mM}\right.$ HEPES, $5 \mathrm{mM}$ glutamate, $5 \mathrm{mM}$ malate, $\mathrm{pH}$ 7.4) were added to the wells at desired time points to introduce $20 \mathrm{nmol} \mathrm{Ca}^{2+}$ to the mitochondrial preparation. 
All swelling assays and Cyt $\mathrm{C}$ release assays were performed in a solution containing $120 \mathrm{mM} \mathrm{KCl}, 5 \mathrm{mM} \mathrm{KH} \mathrm{PO}_{4}$ and $10 \mathrm{mM}$ Tris (pH 7.6). Mitochondrial swelling was evaluated by measuring light scattering of $250 \mu \mathrm{g}$ of mitochondria in a 1 -ml volume at $540 \mathrm{~nm}$ in response to $250 \mu \mathrm{M} \mathrm{CaCl}_{2}$. For Cyt C release, $40 \mu \mathrm{g}$ of cortical neuron mitochondria in a $60-\mu \mathrm{l}$ volume was incubated at $30^{\circ} \mathrm{C}$ with different doses of $\mathrm{H}_{2} \mathrm{O}_{2}$ or $\mathrm{CaCl}_{2}$. To detect the $\mathrm{H}_{2} \mathrm{O}_{2}$-induced Cyt $\mathrm{C}$ release in whole neurons, we incubated neurons with $\mathrm{H}_{2} \mathrm{O}_{2}$ for $1 \mathrm{~h}$ at $37^{\circ} \mathrm{C}$. Then, the neurons were fixed with $4 \%$ paraformaldehyde, permeabilized with $0.5 \%$ Triton X-100 and immune stained with an anti-Cyt $\mathrm{C}$ antibody.

The calcein- $\mathrm{CoCl}_{2}$ bleaching assay was used to test the opening of MPT pores. Cultured neurons (grown both at the bottom of the well and on glass coverslips placed in wells of a 24-well plate) were preincubated with $2 \mu \mathrm{M}$ calcein-AM and $1 \mathrm{mM} \mathrm{CoCl}{ }_{2}$ at $37^{\circ} \mathrm{C}$ for $30 \mathrm{~min}$ and then washed three times with a phenol red-free culture medium. After addition of $\mathrm{H}_{2} \mathrm{O}_{2}(1 \mathrm{mM})$, the fluorescence intensities (excitation, $494 \mathrm{~nm}$; emission, $517 \mathrm{~nm}$ ) of neurons that grew at the bottom of the well were monitored by bottom reading using the SpectraMax Paradigm Multimode Microplate Reader. After reading, the glass coverslips were removed from the wells, fixed and observed by confocal microscopy.

$\Delta \Psi_{\mathrm{m}}$ was measured using TMRM (Invitrogen, Carlsbad, CA, USA). Neurons grown on glass coverslips were loaded with $5 \mathrm{nM}$ TMRM for $10 \mathrm{~min}$, and the fluorescence levels were measured using a confocal microscope with excitation at $543 \mathrm{~nm}$ and emission at $580 \mathrm{~nm}$ at $30 \mathrm{~s}$ intervals while $\mathrm{H}_{2} \mathrm{O}_{2}(100 \mathrm{M})$ was added at 2 min.

For superoxide measurement in live neurons, $2 \mu \mathrm{M}$ Mitosox (Invitrogen) was added to cultured neurons (grown on glass coverslips placed in wells of a 24-well plate) at $37^{\circ} \mathrm{C}$ for $30 \mathrm{~min}$. The cells were then washed three times with the phenol red-free culture medium. The fluorescence intensities (excitation, $510 \mathrm{~nm}$; emission, $580 \mathrm{~nm}$ ) of neurons that directly grew at the bottom of the wells were monitored by bottom reading using the SpectraMax Paradigm Multimode Microplate Reader. After that, the glass coverslips were removed from the 24-well plate, fixed and observed by confocal microscopy.

Transfection of $\mathrm{CHO}$ (or HEK 293) cells. CHO (or HEK 293) cells grown in 35-mm dishes were transfected using Lipofectamine 2000 (Invitrogen) according to the standard protocols. Briefly, 1 day after plating, cells $(2 \mathrm{ml}$ of medium per culture) were transfected with $1-3 \mu \mathrm{g}$ of EGFP-ASIC1a, EGFP-vector, $\Delta \mathrm{N}$-EGFP-ASIC1a or $\Delta \mathrm{C}$-EGFP-ASIC1a. In some experiments, $1.5 \mu \mathrm{g}$ of Mito-DsRed was co-transfected with the equal amount of EGFP-ASIC1a. GFP signal was used for identification of transfected cells.

Cell death assay by propidium iodide staining and Cell-Titer Blue assay. Cultured cells were rinsed with PBS and incubated with $10 \mathrm{mg} / \mathrm{ml}$ propidium iodide (PI) (Sigma-Aldrich) for $10 \mathrm{~min}$ and then rinsed with PBS. Cells were observed shortly after staining by fluorescence microscopy. Cultured mouse cortical neurons were treated with different doses of $\mathrm{H}_{2} \mathrm{O}_{2}(5,10$ and $50 \mu \mathrm{M})$, and the cell death was evaluated by PI staining at different time points $(4,8$ and $20 \mathrm{~h})$. NeuN or DIC was used to identify dead neurons from dead glial cells. This assay was performed double blindly. At least 200 neurons were calculated for each group.

For Cell-Titer Blue (CTB) assay (Promega, Fitchburg, WI, USA), neurons were cultured in wells of 24-well plates. Before treatments, the amount of culture medium was adjusted to the same in each well $(0.5 \mathrm{ml})$. Eight hours later, $0.1 \mathrm{ml}$ of CTB solution was added to each well, and the plate was incubated for $2 \mathrm{~h}$ at $37^{\circ} \mathrm{C}$. Then, the fluorescence intensities (excitation, $560 \mathrm{~nm}$; emission, $590 \mathrm{~nm}$ ) were detected using the SpectraMax Paradigm Multimode Microplate Reader.

Co-IP and western blotting. Mouse cortex, cell pellet or purified mitochondria were collected and resuspended in a lysis buffer $(20 \mathrm{mM}$ Tris-Cl $(\mathrm{pH} 7.4), 150 \mathrm{mM} \mathrm{NaCl}, 1 \%$ Triton X-100, $1 \mathrm{mM}$ EDTA, $3 \mathrm{mM} \mathrm{NaF}, 1 \mathrm{mM}$ $\beta$-gylcerophosphate, $1 \mathrm{mM}$ sodium orthovanadate, $1 \mathrm{mM} \mathrm{Na}_{3} \mathrm{VO}_{4}$ and $10 \%$ glycerol and complete protease inhibitor set (Sigma-Aldrich) and phosphatase inhibitor set (Roche, Temecula, CA, USA)). The resuspended lysates were vortexed for $20 \mathrm{~s}$ and then incubated on ice for $30 \mathrm{~min}$ and centrifuged at 13000 r.p.m. for $15 \mathrm{~min}$. The supernatants were collected for western blot analysis or IP.

For co-IP, lysates were incubated with $3 \mu \mathrm{g}$ anti-ASIC1a antibody or control IgG overnight at $4{ }^{\circ} \mathrm{C}$. In the next day, $30 \mu \mathrm{l}$ protein $\mathrm{G}$ agarose beads (Pierce, Rockford, IL, USA), which were precleared with $5 \mathrm{mg} / \mathrm{ml}$ bovine serum albumin (Sigma-Aldrich), were added into the cell (or tissue) lysates and incubated for $2 \mathrm{~h}$ at $4{ }^{\circ} \mathrm{C}$. Then, the beads were washed three times with lysis buffer, and the immunoprecipitants were eluted with $2 \times$ loading buffer and subjected to western blot analysis.
Computer image analysis: cytofluorograms and the crosscorrelation function. Both cytofluorograms and the cross-correlation function were used to evaluate the overall trend of colocalization between two images in comparison ${ }^{47}$ with the software ImageJ (plugin, JaCoP).

Statistical analysis. Statistical comparisons were performed using unpaired or paired Student's $t$-tests, where values of $P<0.05$ are considered significant.

\section{Conflict of Interest}

The authors declare no conflict of interest.

Acknowledgements. We thank Dr. Qian Hu, Hui Cao, Qiang Song and Yan-Jiao Wu for the technical assistance. This study was supported by grants from the National Natural Science Foundation of China (nos. 31230028, 91213306 and 91132303), US National Institutes of Health (R01GM081658), Shanghai Municipal Education Commission (Leading Academic Discipline Project, J50201) and Shanghai Committee of Science and Technology (11DZ2260200). We also thank Dr. MJ Welsh (Howard Hughes Medical Institute, University of lowa, lowa City, IA, USA) for providing ASIC1a-knockout mice. Yi-Zhi Wang was a postdoctoral fellow supported by the fund from the China Postdoctoral Science Foundation.

1. Wemmie JA, Price MP, Welsh MJ. Acid-sensing ion channels: advances, questions and therapeutic opportunities. Trends Neurosci 2006; 29: 578-586.

2. Ziemann AE, Allen JE, Dahdaleh NS, Drebot II, Coryell MW, Wunsch AM et al. The amygdala is a chemosensor that detects carbon dioxide and acidosis to elicit fear behavior. Cell 2009; 139: 1012-1021.

3. Wemmie JA, Chen J, Askwith CC, Hruska-Hageman AM, Price MP, Nolan BC et al. The acid-activated ion channel ASIC contributes to synaptic plasticity, learning, and memory. Neuron 2002; 34: 463-477.

4. Duan B, Wu LJ, Yu YQ, Ding Y, Jing L, Xu L et al. Upregulation of acid-sensing ion channel ASIC1a in spinal dorsal horn neurons contributes to inflammatory pain hypersensitivity. J Neurosci 2007; 27: 11139-11148.

5. Xiong ZG, Zhu XM, Chu XP, Minami M, Hey J, Wei WL et al. Neuroprotection in ischemia: blocking calcium-permeable acid-sensing ion channels. Cell 2004; 118: 687-698.

6. Gao J, Duan B, Wang DG, Deng XH, Zhang GY, Xu L et al. Coupling between NMDA receptor and acid-sensing ion channel contributes to ischemic neuronal death. Neuron 2005; 48: 635-646.

7. Duan B, Wang YZ, Yang T, Chu XP, Yu Y, Huang $Y$ et al. Extracellular spermine exacerbates ischemic neuronal injury through sensitization of ASIC1a channels to extracellular acidosis. J Neurosci 2011; 31: 2101-2112.

8. Duan B, Liu DS, Huang Y, Zeng WZ, Wang X, Yu H et al. PI3-kinase/Akt pathwayregulated membrane insertion of acid-sensing ion channel 1a underlies BDNF-induced pain hypersensitivity. J Neurosci 2012; 32: 6351-6363.

9. Krishtal O. The ASICs: signaling molecules? Modulators? Trends Neurosci 2003; 26: 477-483.

10. Moskowitz MA, Lo EH, ladecola C. The science of stroke: mechanisms in search of treatments. Neuron 2010; 67: 181-198.

11. Suwanwela N, Koroshetz WJ. Acute ischemic stroke: overview of recent therapeutic developments. Annu Rev Med 2007; 58: 89-106.

12. Simon RP. Acidotoxicity trumps excitotoxicity in ischemic brain. Arch Neurol 2006; 63 : 1368-1371.

13. Mattson MP, Gleichmann M, Cheng A. Mitochondria in neuroplasticity and neurological disorders. Neuron 2008; 60: 748-766.

14. Kroemer G, Galluzzi L, Brenner C. Mitochondrial membrane permeabilization in cell death. Physiol Rev 2007; 87: 99-163.

15. O'Rourke B. Mitochondrial ion channels. Annu Rev Physiol 2007; 69: 19-49.

16. Rasola A, Bernardi P. Mitochondrial permeability transition in $\mathrm{Ca}(2+)$-dependent apoptosis and necrosis. Cell Calcium 2011; 50: 222-233.

17. Schinzel AC, Takeuchi O, Huang Z, Fisher JK, Zhou Z, Rubens J et al. Cyclophilin D is a component of mitochondrial permeability transition and mediates neuronal cell death after focal cerebral ischemia. Proc Natl Acad Sci USA 2005; 102: 12005-12010.

18. Nakagawa T, Shimizu S, Watanabe T, Yamaguchi O, Otsu K, Yamagata $\mathrm{H}$ et al. Cyclophilin D-dependent mitochondrial permeability transition regulates some necrotic but not apoptotic cell death. Nature 2005; 434: 652-658.

19. Baines CP, Kaiser RA, Purcell NH, Blair NS, Osinska H, Hambleton MA et al. Loss of cyclophilin $\mathrm{D}$ reveals a critical role for mitochondrial permeability transition in cell death. Nature 2005; 434: 658-662.

20. Brenner C, Moulin M. Physiological roles of the permeability transition pore. Circ Res 2012; 111: $1237-1247$.

21. Giorgio V, von Stockum S, Antoniel M, Fabbro A, Fogolari F, Forte M et al. Dimers of mitochondrial ATP synthase form the permeability transition pore. Proc Natl Acad Sci USA 2013; 110: 5887-5892. 
22. Bauer MK, Schubert A, Rocks O, Grimm S. Adenine nucleotide translocase-1, a component of the permeability transition pore, can dominantly induce apoptosis. J Cell Biol 1999; 147: 1493-1502.

23. Diochot S, Baron A, Salinas M, Douguet D, Scarzello S, Dabert-Gay AS et al. Black mamba venom peptides target acid-sensing ion channels to abolish pain. Nature 2012 490: 552-555.

24. Zha XM, Wang R, Collier DM, Snyder PM, Wemmie JA, Welsh MJ. Oxidant regulated intersubunit disulfide bond formation between ASIC1a subunits. Proc Natl Acad Sci USA 2009; 106: 3573-3578.

25. Polla BS, Kantengwa S, Francois D, Salvioli S, Franceschi C, Marsac C et al. Mitochondria are selective targets for the protective effects of heat shock against oxidative injury. Proc Natl Acad Sci USA 1996; 93: 6458-6463.

26. Orrenius S, Gogvadze V, Zhivotovsky B. Mitochondrial oxidative stress: implications for cell death. Annu Rev Pharmacol Toxicol 2007; 47: 143-183.

27. Murphy AN, Bredesen DE, Cortopassi G, Wang E, Fiskum G. Bcl-2 potentiates the maximal calcium uptake capacity of neural cell mitochondria. Proc Natl Acad Sci USA 1996; 93: 9893-9898.

28. Chai S, Li M, Branigan D, Xiong ZG, Simon RP. Activation of acid-sensing ion channel 1 a (ASIC1a) by surface trafficking. J Biol Chem 2010; 285: 13002-13011.

29. Pallotti $F$, Lenaz $G$. Isolation and subfractionation of mitochondria from animal cells and tissue culture lines. Methods Cell Biol 2007; 80: 3-44.

30. Hayashi T, Rizzuto R, Hajnoczky G, Su TP. MAM: more than just a housekeeper. Trends Cell Biol 2009; 19: 81-88.

31. de Brito OM, Scorrano L. Mitofusin 2 tethers endoplasmic reticulum to mitochondria Nature 2008; 456: 605-610.

32. Neupert W, Herrmann JM. Translocation of proteins into mitochondria. Annu Rev Biochem 2007; 76: 723-749.

33. Dalle-Donne I, Aldini G, Carini M, Colombo R, Rossi R, Milzani A. Protein carbonylation, cellular dysfunction, and disease progression. J Cell Mol Med 2006; 10: 389-406.

34. Benard G, Massa F, Puente N, Lourenco J, Bellocchio L, Soria-Gomez E et al Mitochondrial $\mathrm{CB}(1)$ receptors regulate neuronal energy metabolism. Nat Neurosci 2012 15: $558-564$.

35. Korde AS, Maragos WF. Identification of an $N$-methyl-D-aspartate receptor in isolated nervous system mitochondria. J Biol Chem 2012; 287: 35192-35200.
36. Wang $\mathrm{YZ}, \mathrm{Xu} \mathrm{TL}$. Acidosis, acid-sensing ion channels, and neuronal cell death. $\mathrm{Mol}$ Neurobiol 2011; 44: 350-358

37. Azarias G, Van de Ville D, Unser M, Chatton JY. Spontaneous NA ${ }^{+}$transients in individual mitochondria of intact astrocytes. Glia 2008; 56: 342-353.

38. Santo-Domingo J, Demaurex N. Perspectives on: SGP symposium on mitochondrial physiology and medicine: the renaissance of mitochondrial pH. J Gen Physiol 2012; 139: 415-423.

39. Friese MA, Craner MJ, Etzensperger R, Vergo S, Wemmie JA, Welsh MJ et al. Acidsensing ion channel-1 contributes to axonal degeneration in autoimmune inflammation of the central nervous system. Nat Med 2007; 13: 1483-1489.

40. Arias RL, Sung ML, Vasylyev D, Zhang MY, Albinson K, Kubek K et al. Amiloride is neuroprotective in an MPTP model of Parkinson's disease. Neurobiol Dis 2008; 31 : 334-341.

41. Wong HK, Bauer PO, Kurosawa M, Goswami A, Washizu C, Machida Y et al. Blocking acid-sensing ion channel 1 alleviates Huntington's disease pathology via an ubiquitin-proteasome system-dependent mechanism. Hum Mol Genet 2008; 17: 3223-3235.

42. Peixoto PM, Ryu SY, Kinnally KW. Mitochondrial ion channels as therapeutic targets. FEBS Lett 2010; 584: 2142-2152.

43. Behan AT, Breen B, Hogg M, Woods I, Coughlan K, Mitchem M et al. Acidotoxicity and acid-sensing ion channels contribute to motoneuron degeneration. Cell Death Differ 2013; 20: $589-598$.

44. Zha XM, Wemmie JA, Green SH, Welsh MJ. Acid-sensing ion channel 1a is a postsynaptic proton receptor that affects the density of dendritic spines. Proc Natl Acad Sci USA 2006; 103: 16556-16561.

45. Kruman II, Pedersen WA, Springer JE, Mattson MP. ALS-linked Cu/Zn-SOD mutation increases vulnerability of motor neurons to excitotoxicity by a mechanism involving increased oxidative stress and perturbed calcium homeostasis. Exp Neurol 1999; 160: 28-39.

46. Dutta R, McDonough J, Yin X, Peterson J, Chang A, Torres $T$ et al. Mitochondrial dysfunction as a cause of axonal degeneration in multiple sclerosis patients. Ann Neurol 2006; 59: 478-489.

47. Bolte S, Cordelieres FP. A guided tour into subcellular colocalization analysis in light microscopy. J Microsc 2006; 224(Pt 3): 213-232.

Supplementary Information accompanies this paper on the Cell Death and Differentiation website (http://www.nature.com/cdd) 